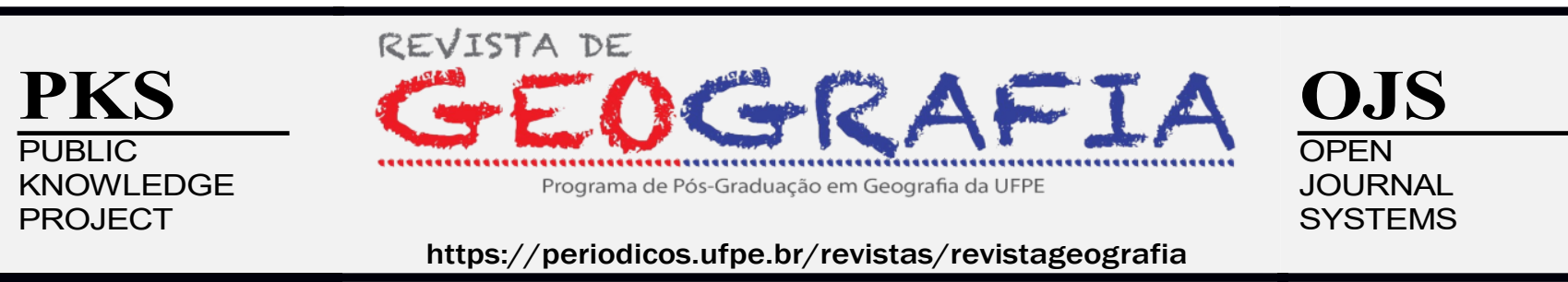

\title{
VULNERABILIDADE NATURAL À EROSÃO NAS ÁREAS DE CAFÉ E PASTAGEM NO MUNICÍPIO DE CACHOEIRO DE ITAPEMIRIM (ES)
}

\author{
Caio Henrique Ungarato Fiorese ${ }^{1}$
}

\begin{abstract}
${ }^{1}$ Mestrando em Agroquímica - Universidade Federal do Espírito Santo. E-mail:caiofiorese@hotmail.com. Orcid: http://orcid.org/0000-0001-6866-0361
\end{abstract}

Artigo recebido em 27/01/2021 e aceito em 12/07/2021

\begin{abstract}
RESUMO
A erosão hídrica do solo pode reduzir a produção agrícola e pecuária e causar danos ambientais severos. O objetivo deste estudo foi avaliar as perdas potenciais de solo das áreas de cafeicultura e pastagem do município de Cachoeiro de Itapemirim (ES), como forma de subsidiar melhorias em produtividade e planejamento na agropecuária e conservação dos solos. Os procedimentos ocorreram no programa ArcGIS. No GEOBASES, foram adquiridos arquivos vetoriais referentes à localização das pastagens e dos cafezais. Considerando a Equação Universal de Perda de Solos, foram obtidos os parâmetros: declividade, comprimento de rampa, erosividade e erodibilidade. A fim de verificar possíveis formações erosivas, no programa Google Earth Pro, foram registradas imagens aéreas. Na cafeicultura, a maior classe de intensidade é a "moderada a forte", com $57,842 \%$. Mas, juntas, as classes compreendidas de "moderada a forte" a "muito forte" somam 71,24\%. Nas pastagens, a intensidade "moderada a forte" abrange $50,942 \%$ e as classes "fraca" e "moderada" somam $41,864 \%$. Foram registradas várias formações erosivas, como voçorocas, principalmente em pastagens. Nos cafezais, há espaços de solo totalmente expostos. É relevante a adoção de medidas conservacionistas, além de trabalhos de conscientização e assistência técnica com os produtores rurais acerca da vulnerabilida de à erosão.
\end{abstract}

Palavras-chave: Cultivo do Café; Conservação dos Solos; Impactos Ambientais; Mitigação; Pecuária.

\section{NATURAL VULNERABILITY TO EROSION IN THE COFFEE AND PASTURE AREAS IN THE MUNICIPALITY OF CACHOEIRO DE ITAPEMIRIM (ES)}

\begin{abstract}
Soil water erosion can reduce agricultural and livestock production and cause severe environmental damage. The objective of this study was to evaluate potential soil losses in coffee and pasture areas in the municipality of Cachoeiro de Itapemirim (ES), as a way to subsidize improvements in productivity and planning in
\end{abstract}


agriculture and soil conservation. The procedures took place in the ArcGIS program. In GEOBASES, vector files were acquired regarding the location of pastures and coffee plantations. Considering the Universal Soil Loss Equation, the parameters were obtained: slope, ramp length, erosivity and erodibility. In order to check for possible erosive formations, aerial images were recorded in the Google Earth Pro program. In coffee growing, the highest intensity class is "moderate to strong", with $57.842 \%$. But, together, the classes comprised of "moderate to strong" to "very strong" add up to $71.24 \%$. In pastures, the "moderate to strong" intensity covers $50.942 \%$ and the "weak" and "moderate" classes add up to $41.864 \%$. Various erosive formations have been recorded, such as gullies, mainly in pastures. In coffee plantations, there are fully exposed soil spaces. It is important to adopt conservation measures, in addition to raising awareness and providing technical assistance to rural producers about vulnerability to erosion.

Keywords: Coffee Growing. Soil Conservation. Environmental Impacts. Mitigation. Livestock.

\section{INTRODUÇÃO}

O café chegou ao Estado do Espírito Santo no século XIX, em decorrência da expansão das áreas de cultivo do Vale do Paraíba. A monocultura do café, já no final deste século, era a atividade predominante na agricultura do Estado (FERRÃO et al., 2007). No Brasil, a cafeicultura provocou um crescimento econômico de nítida relevância ao longo de sua história e possibilitou ao país destacar-se como maior produtor de café do mundo. Todavia, muitos impactos socioambientais foram desencadeados durante esse processo. Entre os principais impactos estão o alto índice de desmatamento da Mata Atlântica para implantação dos monocultivos cafeeiros, a contaminação e degradação dos recursos hídricos pelo constante uso dos agroquímicos, o empobrecimento do solo e o desequilíbrio ambiental associado ao surgimento de pragas e doenças que danificam às lavouras (LOPES et al., 2014).

A pecuária é uma atividade de suma relevância no Brasil e a nível mundial. Em relação à evolução das atividades pecuaristas, tem-se com maior perspectiva de crescimento o gado leiteiro, com uma taxa de crescimento de 5,69\% por ano, e o gado de corte, com 3,03\%. Contudo, esta atividade, assim como a cafeicultura, muitas vezes causa impactos negativos ao meio ambiente (WUST; TAGLIANI; CONCATO, 2015). Apesar de a pecuária possuir grande importância na economia brasileira e contar com pesquisa e infraestrutura, ainda é perceptível que extensas áreas são destinadas aos cultivos de pastagens que, consequentemente, favorecem o processo de degradação das propriedades físicas, químicas e biológicas do solo, quando planejada indevidamente. Essa situação compromete a sustentabilidade do ecossistema (GALHARTE; CRESTANA, 2010).

A degradação dos solos é um dos principais problemas socioambientais em áreas usadas para a agropecuária no Brasil. Os levantamentos e as estimativas atuais apontam que a deteriorização dos solos brasileiros ocorre principalmente na forma de processos erosivos acelerados, desencadeados 
pelo escoamento difuso ou concentrado da água das chuvas na superfície do solo. Neste sentido, diversas formas de erosão podem ocorrer, como a laminar, em sulcos, ravinas e voçorocas (SOUZA; GASPARETTO, 2012). A erosão é uma das formas mais prejudiciais de degradação do solo. Além de reduzir o potencial produtivo das culturas agrícolas, pode causar sérios danos ambientais, como a alteração dos ecossistemas aquáticos devido à poluição dos recursos hídricos e ao assoreamento dos cursos d'água (BARBOSA et al., 2015).

Uma relevante preocupação no planejamento conservacionista é a erosão hídrica, que provoca diversos impactos ambientais na área rural, tais como: perda da biodiversidade, danos à qualidade da água, queda na produtividade agrícola e pecuária, assoreamento de rios e surgimento de processos de desertificação (MATA, 2009). A erosão hídrica inicia-se com a desagregação das partículas do solo sob ação do impacto das gotas de chuva. A enxurrada transporta os sedimentos ao longo das vertentes até atingir os mananciais, causando assoreamento dos cursos d'água. O assoreamento reduz a profundidade dos canais e causa poluição das águas, alterando a dinâmica das águas superficiais (COSTA, 2005).

Diante das preocupações dos problemas da erosão, com o passar dos anos, foram desenvolvidos modelos matemáticos capazes de estimar a erosão dos solos. Um desses modelos é a Equação Universal de Perda do Solo (sigla em inglês: USLE). Criada por Wischmeier e Smith (1962) e, na sua forma mais genérica, permite estimar a erosão sob diversas condições de uso e cobertura do solo, declividade, comprimento de rampa, tipos de solo e chuva, por meio da elaboração de mapas temáticos. Representa importante ferramenta de estudo sobre o processo erosivo e permite a segmentação da paisagem em níveis de instabilidade (BARBOSA et al., 2015).

A integração de dados e informações sobre os aspectos fisiográficos e socioeconômicos de uma bacia hidrográfica permite que se alcance diversos resultados de interesse. Para este fim, a utilização de um Sistema de Informação Geográfica (SIG) oferece grandes vantagens. O SIG tem como principal função armazenar, recuperar e analisar mapas, realizando combinações destas informações. Os cruzamentos automatizados de informação fornecem, além de uma elevada exatidão do produto final, uma grande economia de tempo em relação aos métodos de análise tradicionais. Ou seja, o planejamento de manejo e conservação de solo e água de alguma área, como cultivos agrícolas e pastagem, pode ser feito com maior precisão e rapidez por meio do SIG (MARQUES; LOMBARDI NETO; BACELLAR, 2020).

Assim, o objetivo deste estudo foi avaliar as perdas potenciais de solo das áreas de cafeicultura e pastagem do município de Cachoeiro de Itapemirim, Espírito Santo, a fim de subsidiar 
melhorias em termos de produtividade e planejamento na agropecuária e conservação dos solos na região.

\section{MATERIAL E MÉTODOS}

O município de Cachoeiro de Itapemirim está localizado na mesorregião Sul do Estado do Espírito Santo, mais precisamente nas coordenadas geográficas $20^{\circ} 50^{\prime} 56^{\prime \prime}$ de latitude Sul e $41^{\circ} 06^{\prime} 46^{\prime \prime}$ de longitude Oeste. Situa-se em área com solos de baixa e média fertilidade, com topografia predominantemente ondulada e acidentada. O clima é tropical, com média pluviométrica igual a 1.200 mm, havendo duas estações distintas: a seca, correspondente aos meses de abril a setembro, e a chuvosa, que abrange o período de outubro a março. Possui a cafeicultura e pecuária como as principais atividades econômicas na área rural (INCAPER, 2010).

Os procedimentos ocorreram utilizando-se de SIG, no programa computacional ArcGIS®. Os bancos de dados cartográficos foram adquiridos nos portais eletrônicos do Sistema Integrado de Bases Geoespaciais do Estado do Espírito Santo (GEOBASES, 2020), do Instituto Jones dos Santos Neves (IJSN, 2020) e da Agência Nacional de Águas (ANA, 2020). No GEOBASES, inicialmente, foram adquiridas feições de curvas de nível com equidistância de $5 \mathrm{~m}$ referentes ao município considerado. Em layout do programa, foram adicionados os arquivos para, posteriormente, gerar o Modelo Digital de Elevação (MDE).

$\mathrm{Na}$ identificação das áreas ocupadas por pastagem e cafeicultura, foram adquiridas, no GEOBASES, feições de pastagem mapeadas nos anos de 2012 a 2015, em escala igual ou melhor a 1:25000. No ArcGIS ${ }^{2}$, as mesmas feições foram editadas, expondo somente as áreas de cafeicultura e pastagem do município de Cachoeiro de Itapemirim por meio de ferramentas de recorte de arquivos. A Figura 1 demonstra a localização das áreas de cafeicultura e pastagem. 
Figura 1 - Localização das áreas de pastagem e cafeicultura

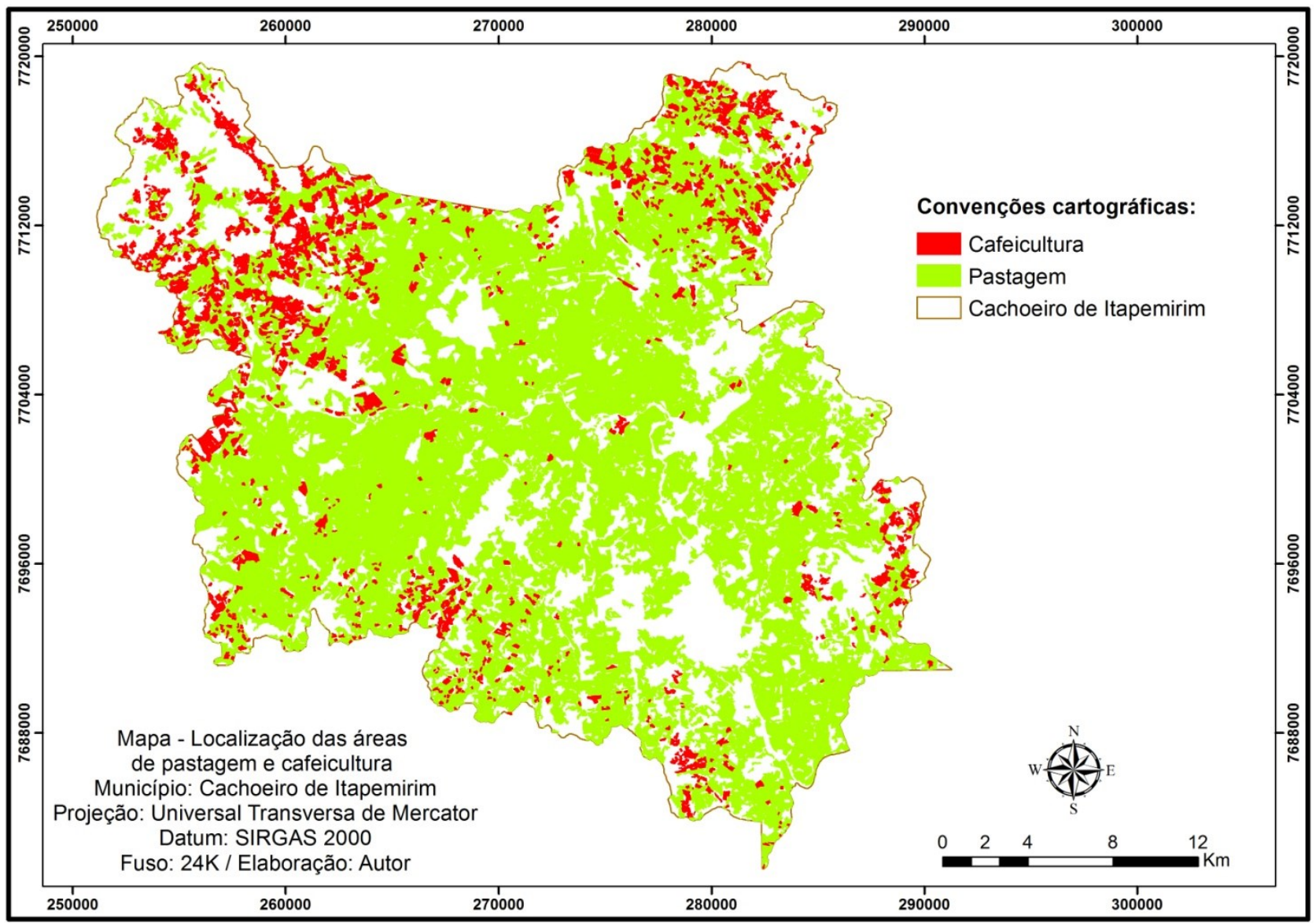

Fonte: Adaptado de Geobases (2020).

A Equação Universal de Perda dos Solos, considerada na estimativa da erosão potencial neste trabalho, é dada pela equação (1):

$$
\mathrm{A}=\mathrm{R} \times \mathrm{L} \times \mathrm{S} \times \mathrm{K} \times \mathrm{C} \times \mathrm{P}
$$

Em que: $\mathrm{A}=$ perda de solo ( $\mathrm{t}$ ha-1 ano-1); $\mathrm{R}$ = erosividade da chuva (MJ ha-1 $\mathrm{mm}$ h-1 ano1); $\mathrm{K}=$ erodibilidade do solo [t ha-1 (MJ ha-1 $\mathrm{mm} \mathrm{h-1)-1];} \mathrm{L}=$ comprimento do declive (adimensional); $\mathrm{S}=$ grau de declive (adimensional); $\mathrm{C}=$ uso e manejo do solo (adimensional) e; $\mathrm{P}=$ práticas conservacionistas (adimensional). A erosão atual, não trabalhada neste estudo, indica as perdas de solo por erosão hídrica considerando a erosão potencial e as condições atuais de uso do solo e práticas culturais, ou seja, os valores de C e P (DURÃES; MELLO, 2016). Portanto, para este trabalho, não foram considerados os fatores C e P da USLE. 
A capacidade da chuva de causar erosão em uma área desprotegida em uma dada localidade é expressa pelo fator numérico R (WISCHMEIER; SMITH, 1962), que deve ser calculado a partir de índices mensais de erosão, obtidos pela equação (2), elaborada por Lombardi Neto e Moldenhauer (1992):

$$
\text { EI } \mathrm{i}=67,355 \times\left(\frac{\mathrm{ri}^{2}}{\mathrm{Pi}^{2}}\right)^{0,85}
$$

Em que: EI i = média mensal do índice de erosão $\left(\mathrm{MJ} \mathrm{ha}^{-1} \mathrm{~mm}^{-1}\right)$; ri = precipitação pluvial média mensal $(\mathrm{mm}) ; \mathrm{Pi}=$ média anual da precipitação pluviométrica $(\mathrm{mm})$. $\mathrm{O}$ fator $\mathrm{R}$ significa $\mathrm{O}$ somatório dos valores mensais de erosividade (BERTONI; LOMBARDI NETO, 1999). Os dados de precipitação foram adquiridos no sítio eletrônico Hidroweb, da Agência Nacional de Águas (ANA, 2020), referentes a uma estação pluviométrica localizada no município de Cachoeiro de

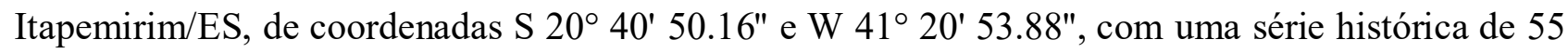
anos.

Através do Modelo Digital de Elevação (MDE) com resolução de 15 m gerado a partir das feições de curvas de nível, foi gerado o mapa de declividade através da função "slope" no ArcGIS para, em seguida, obter os fatores L e S da EUPS. Na prática, esses dois fatores são considerados conjuntamente, por meio de um termo designado fator topográfico ou LS, que é obtido a partir da agregação do comprimento das encostas (vertentes) com o gradiente de declividade (grau de inclinação), por meio de modelos matemáticos (GALDINO, 2012). O fator topográfico (LS) da equação foi gerado a partir da geração de dois mapas. O mapa do fator L foi obtido com auxílio da metodologia de Desmet e Govers (1996), McCool, Brown e Foster (1987) e McCool et al. (1989), através das equações (3), (4) e (5).

$$
\begin{aligned}
& \mathrm{F}=\frac{\sin \mathrm{C} / 0,0896}{0,56+3(\sin \mathrm{C})^{0,8}} \\
& \mathrm{~m}=\frac{\mathrm{F}}{1+\mathrm{F}^{\prime}} \\
& \mathrm{L}=\frac{\left[\mathrm{A}+\mathrm{D}^{2}\right]^{(\mathrm{m}+1)}-\mathrm{A}^{\mathrm{m}+1}}{\mathrm{x}^{\mathrm{m}} \mathrm{D}^{\mathrm{m}+2}(22,13)^{\mathrm{m}}}
\end{aligned}
$$

Em que: $\mathrm{D}=$ tamanho do pixel; $\mathrm{A}=$ fluxo acumulado da drenagem (obtido no ArcGIS®, a partir do MDE da área e da posterior obtenção da direção do fluxo de drenagem); $\mathrm{C}=$ declividade 
(expressa e convertida em radianos); $\mathrm{x}=$ coeficiente de forma (adotado $\mathrm{x}=1$, para sistemas compostos por pixels); $\mathrm{m}, \mathrm{F}=$ coeficientes (adimensional). Em seguida, foi gerado o mapa do fator $\mathrm{S}$, pelo algoritmo de McCool, Brown e Foster (1987) e McCool et al. (1989), partindo das seguintes condições, considerando a declividade: quando $\tan \mathrm{C}<0,09$, adotar $\mathrm{S}=10,8 \sin (\mathrm{C})+0,03$ e; quando $\tan \mathrm{C} \geq 0,09$, adotar $\mathrm{S}=16,8 \sin (\mathrm{C})+0,5$.

Alguns solos apresentam maior propensão à erosão que outros, mesmo quando a cobertura vegetal, a precipitação, o declive e as práticas de controle de erosão são as mesmas. Essa diferença é chamada de erodibilidade do solo (fator $\mathrm{K}$ ) e ocorre devido às propriedades inerentes ao solo (BERTONI; LOMBARDI NETO, 1999). O fator K (erodibilidade do solo) foi determinado inicialmente, a partir do mapeamento dos tipos de solos das áreas de café e pastagem e, em seguida, pela consulta dos dados conforme os valores considerados por Demarchi e Zimback (2014), Lanzanova (2009), Morais e Sales (2017) e Silva, Paiva e Santos (2009). A inserção das equações foi realizada na ferramenta "raster calculator", também conhecida como álgebra de mapas, que permite trabalhar com mapas produzidos a partir de equações inseridas no programa. Após a obtenção de todos os componentes da equação, a erosão foi classificada conforme o método de Durães e Mello (2016).

No intuito de verificar a ocorrência de formações erosivas nas áreas de pastagem e cafeicultura do município de Cachoeiro de Itapemirim, no programa Google Earth Pro, foram coletadas imagens aéreas que evidenciassem possíveis problemas inerentes à erosão nas áreas estudadas. Essas imagens foram registradas nas datas mais recentes possíveis (considerando os anos de 2019 e 2020). Foram coletadas as coordenadas geográficas de cada imagem, tornando-se possível a localização das áreas fotografadas e a sua observação quanto ao potencial natural de erosão.

\section{RESULTADOS E DISCUSSÃO}

A erosividade estimada foi igual a 7.516,91 $\mathrm{MJ} \mathrm{ha}^{-1} \mathrm{~mm}^{-1}$. Esse valor pode ser classificado como "forte", segundo a classificação de Carvalho (2008). Quanto à classificação dos solos, foram detectados 6 tipos diferentes para as áreas de pastagem: cambissolo háplico $(K=0,037)$, neossolo litólico $(K=0,048)$, argissolo vermelho $(K=0,044)$, chernossolo argilúvico $(K=0,028)$, latossolo amarelo $(K=0,041)$ e nitossolo vermelho $(K=0,039)$. Já para as áreas de pastagem, foram vistos topos os tipos de solos descritos anteriormente, além do neossolo flúvico $(K=0,037)$.

Os valores de intensidade à erosão potencial das áreas de cafeicultura variam de 5,88 ton/ha.ano a 3.717,435 ton/ha.ano, com média aritmética de 950,975 ton/ha.ano e desvio padrão igual 
a 558,275 ton/ha.ano. A maior classe de erosão é a "moderada a forte", ao passo que a menor classe é a "muito forte". Mas, quando somadas, as classes compreendidas de "moderada a forte" a "muito forte" somam 71,24\% dos cafezais. A Figura 2 e a Tabela 1 mostram, respectivamente, o mapa de erosão potencial dos cafezais e os percentuais de área para cada classe de intensidade à erosão.

Figura 2 - Mapa de erosão potencial das áreas de café

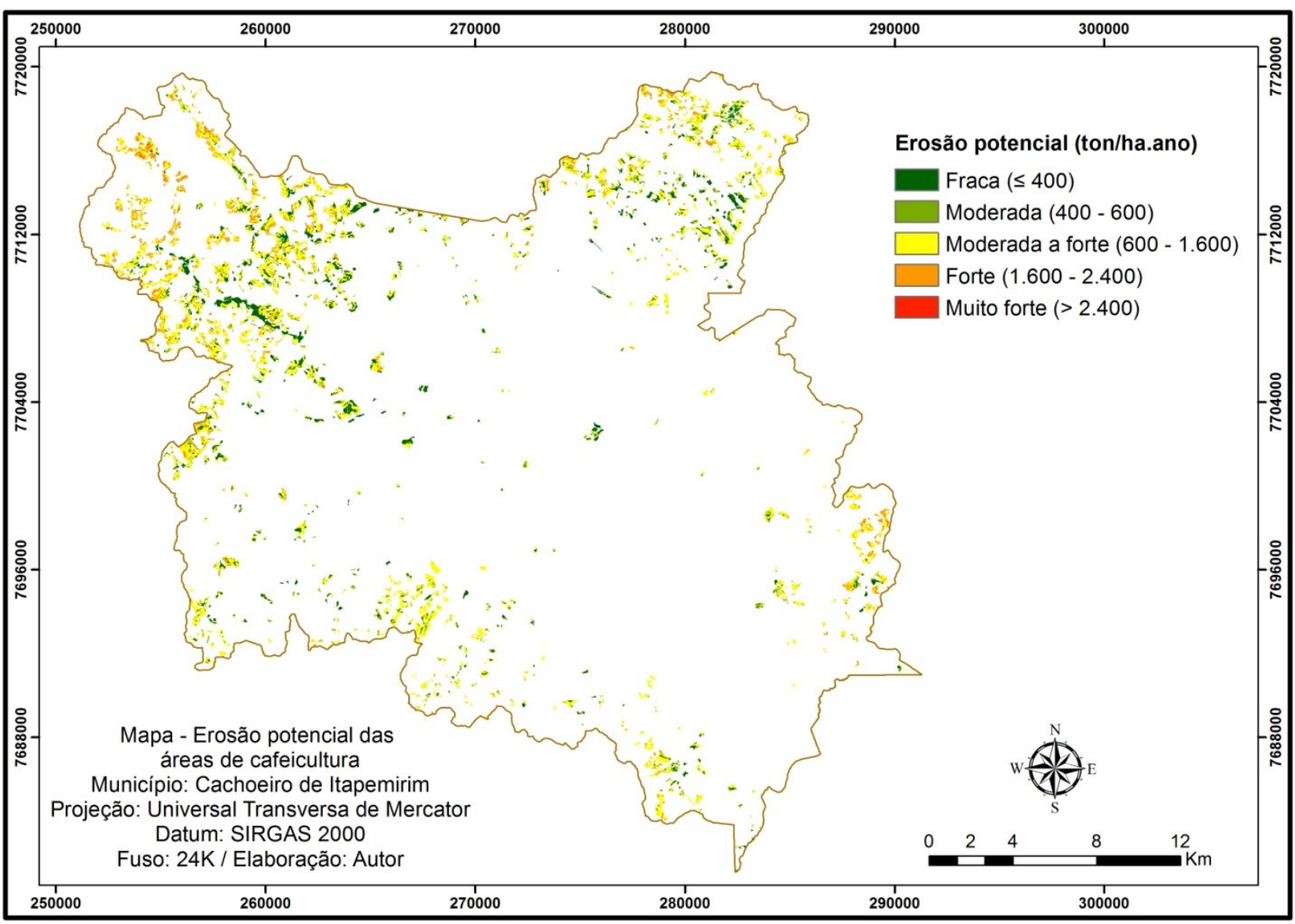

Fonte: O Autor (2020).

Tabela 1 - Área (em \%) para cada classe de intensidade a erosão nas áreas de cafeicultura

\begin{tabular}{lc}
\hline CLASSES (ton/ha.ano) & ÁREA (\%) \\
\hline Fraca $(\leq 400)$ & $19,268 \%$ \\
Moderada (400 - 600) & $9,488 \%$ \\
Moderada a forte (600 - 1.600) & $57,482 \%$ \\
Forte (1.600 - 2.400) & $13,501 \%$ \\
Muito forte (> 2.400) & $0,261 \%$ \\
\hline
\end{tabular}

Fonte: O Autor (2020). 
A maior parte das áreas de cafeicultura, portanto, apresenta tendência mediana a processos erosivos na maior parte. Isso se atribui às características naturais dos locais ocupados, como as irregularidades do relevo (alta declividade, por exemplo) e a erodibilidade, além da falta de conscientização de produtores rurais acerca dos locais mais propícios à prática da cafeicultura. Assim, torna-se um motivo de grande preocupação, pois a cafeicultura, caso não manejada devidamente, pode acarretar impactos ambientais problemáticos. No Estado do Espírito Santo, é perceptível um significativo número de agricultores familiares produtores de café conilon, presente na maior parte da cafeicultura do município de Cachoeiro de Itapemirim. Os mesmos exploram a atividade em áreas pouco vocacionadas, com restrições hídricas e baixa utilização de recursos tecnológicos e financeiros. Isso vem causando uma degradação progressiva dos recursos naturais. Como consequência, ocorre o abandono das terras degradadas e o aumento do êxodo rural (FERRÃO et al., 2007). Tais fatos podem ser evidentes nas áreas de cafeicultura naturalmente mais vulneráveis no município de Cachoeiro de Itapemirim, constituindo um motivo de preocupação quanto ao planejamento das áreas ocupadas pela cafeicultura.

A utilização de encostas íngremes para o cultivo do café nas regiões capixabas sem o uso de práticas conservacionistas adequadas tem causado forte erosão nos solos, levando a sua degradação, com consequente queda da produtividade e longevidade do cafeeiro (ROCHA; PREZOTTI; DADALTO, 2019). Esta característica local de cultivos do café em áreas irregulares, associada aos elevados volumes e intensidades de precipitação pluviométrica (erosividade) nas áreas de maiores altitudes, típicos da estação chuvosa (verão), faz com que o manejo da vegetação por parte do cafeicultor capixaba seja repensado, sob o ponto de vista da sustentabilidade ambiental (PAULA; CABANÊZ; FERRARI, 2013).

Portanto, no município de Cachoeiro de Itapemirim, principalmente nas áreas com intensidade "moderada a forte" a "muito forte" à erosão, são necessárias medidas conservacionistas quanto à qualidade do solo para a produtividade cafeeira. Além do mais, esta pesquisa mostra a necessidade de um correto planejamento na instalação de futuros cafezais no município, priorizando a ocupação destes em áreas naturalmente menos propensas à erosão (com intensidades compreendidas de fraca a moderada).

A intensidade à erosão potencial nas pastagens varia de 5,88 ton/ha.ano a 3.595,548 ton/ha.ano, com média aritmética de 755,771 ton/ha.ano e desvio padrão igual a 551,538 ton/ha.ano. Assim como na cafeicultura, a maior classe de intensidade da erosão nas pastagens é a "moderada a 
forte" e a de menor presença é a "muito forte". Mas, quando somadas, as classes "moderada a forte" a "muito forte" abrangem 58,136\%. A Figura 3 e a Tabela 2 mostram, respectivamente, o mapa de erosão potencial das pastagens e os percentuais de área para cada classe de erosão.

Figura 3 - Mapa de erosão potencial das áreas de pastagem

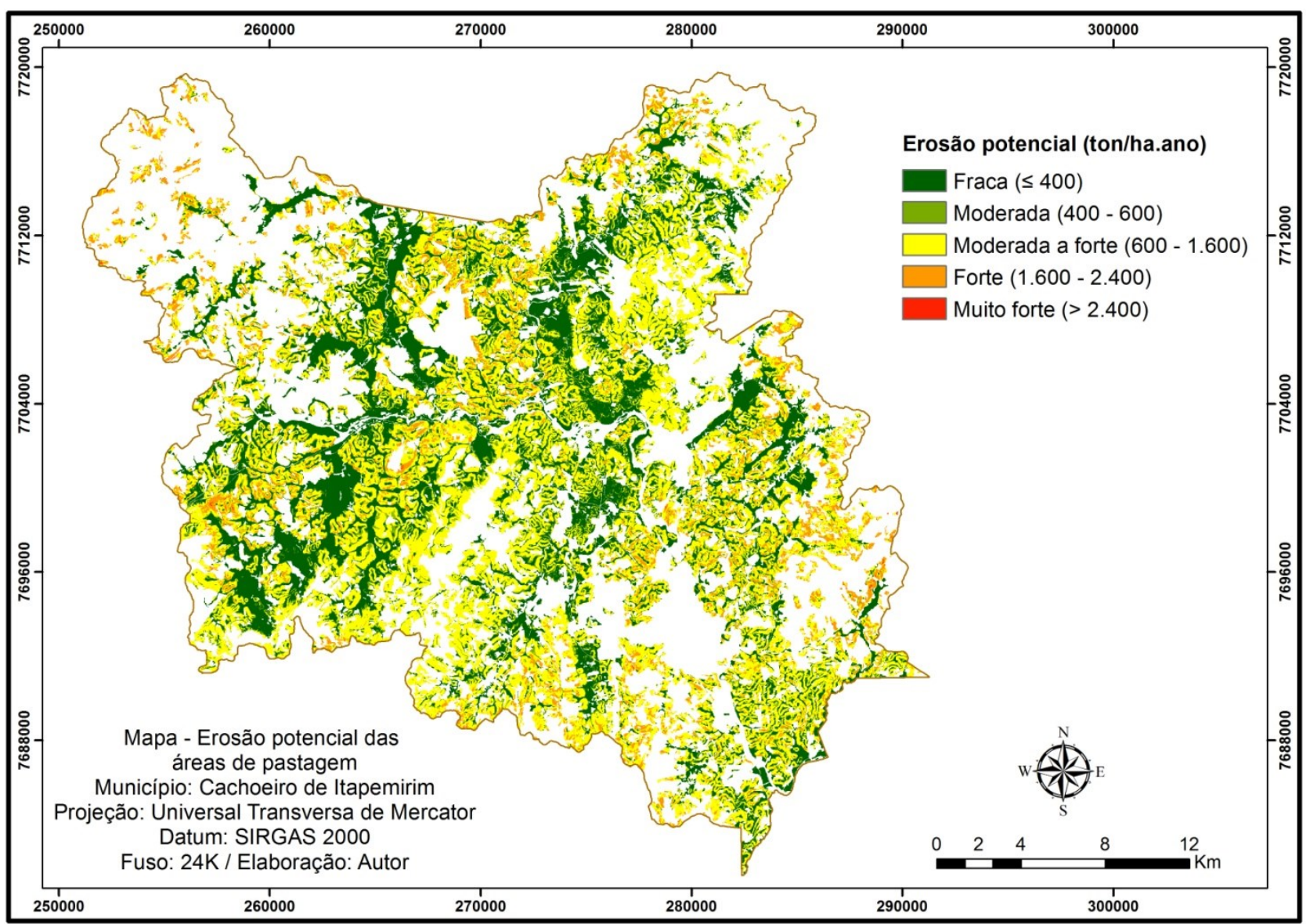

Fonte: O Autor (2020).

Tabela 2 - Área (em \%) para cada classe de intensidade da erosão nas áreas de pastagem

\begin{tabular}{lc}
\hline CLASSES (ton/ha.ano) & ÁREA (\%) \\
\hline Fraca $(\leq 400)$ & $32,694 \%$ \\
Moderada (400 - 600) & $9,170 \%$ \\
Moderada a forte (600 - 1.600) & $50,942 \%$ \\
Forte (1.600 - 2.400) & $7,099 \%$ \\
Muito forte (> 2400) & $0,095 \%$ \\
\hline
\end{tabular}

Fonte: O Autor (2020). 
Os valores, quando comparados com a cafeicultura, são mais satisfatórios. No entanto, também indicam potencialidade média à erosão na maior parte das pastagens, o que está atrelada a fatores naturais, como as irregularidades do relevo e a erodibilidade. Outro fator preocupante é o mau planejamento na ocupação das pastagens, capazes de ocupar áreas naturalmente susceptíveis a erosão (sobretudo aquelas classificadas com intensidade "forte" e "muito forte"). A utilização de uma propriedade agrícola é, em geral, não planejada, contrariando, na maioria das vezes, a sua real capacidade de uso. Isso pode acarretar uma manifestação do processo erosivo do solo, em intensidade e velocidade que ultrapassam os limites de tolerância (MELLO; BUENO; PEREIRA, 2006).

O sistema extensivo, técnica predominante na maior parte das pastagens na região estudada, caracteriza-se pela maioria das propriedades rurais situar-se longe dos grandes centros consumidores, gado a campo, ter produção e/ou produtividade baixa, instalações inadequadas e pastagens com os manejos inapropriados (OLIVEIRA et al., 2008). A pecuária, quando feita sob práticas incorretas de manejo do solo e em áreas naturalmente potenciais a erosão, pode provocar impactos ambientais drásticos, como a perda da qualidade dos solos e a improdutividade da terra. Um dos fatores que favorece o aparecimento desses impactos negativos é a compactação do solo, que é oriunda principalmente da criação de bovinos que utilizam grandes áreas, muitas vezes sem nenhuma forma de manejo (WUST; TAGLIANI; CONCATO, 2015). Além do mais, a erosão causa o comprometimento das propriedades físicas do solo, que é um dos principais fatores de degradação das pastagens que, diante desta situação de solo, reduzem consideravelmente a sua longevidade (PARENTE; MAIA, 2011).

Assim como na cafeicultura do município de Cachoeiro de Itapemirim, é imprescindível uma melhor organização do manejo da pecuária para que seja feito o controle da movimentação do gado, além do aprimoramento de técnicas de sistemas criação (WUST; TAGLIANI; CONCATO, 2015). Portanto, nas áreas com potencialidade a erosão de "moderada a forte" a "muito forte", é imprescindível a adoção de técnicas conservacionistas, além de um melhor planejamento de ocupação de novas áreas destinadas a essa atividade.

Durante o registro de imagens aéreas dos espaços estudados, foram vistas várias formações erosivas, principalmente nas áreas de pasto. Já nos cafezais, embora os mesmos estejam cultivados na técnica de "curvas de nível" na maior parte, há espaços de solo exposto. As Figuras 4 e 5 apresentam as formações erosivas visualizadas para, respectivamente, as áreas de pastagem e cafeicultura. 
Figura 4 - Erosão potencial e as principais formações erosivas nas áreas de pasto

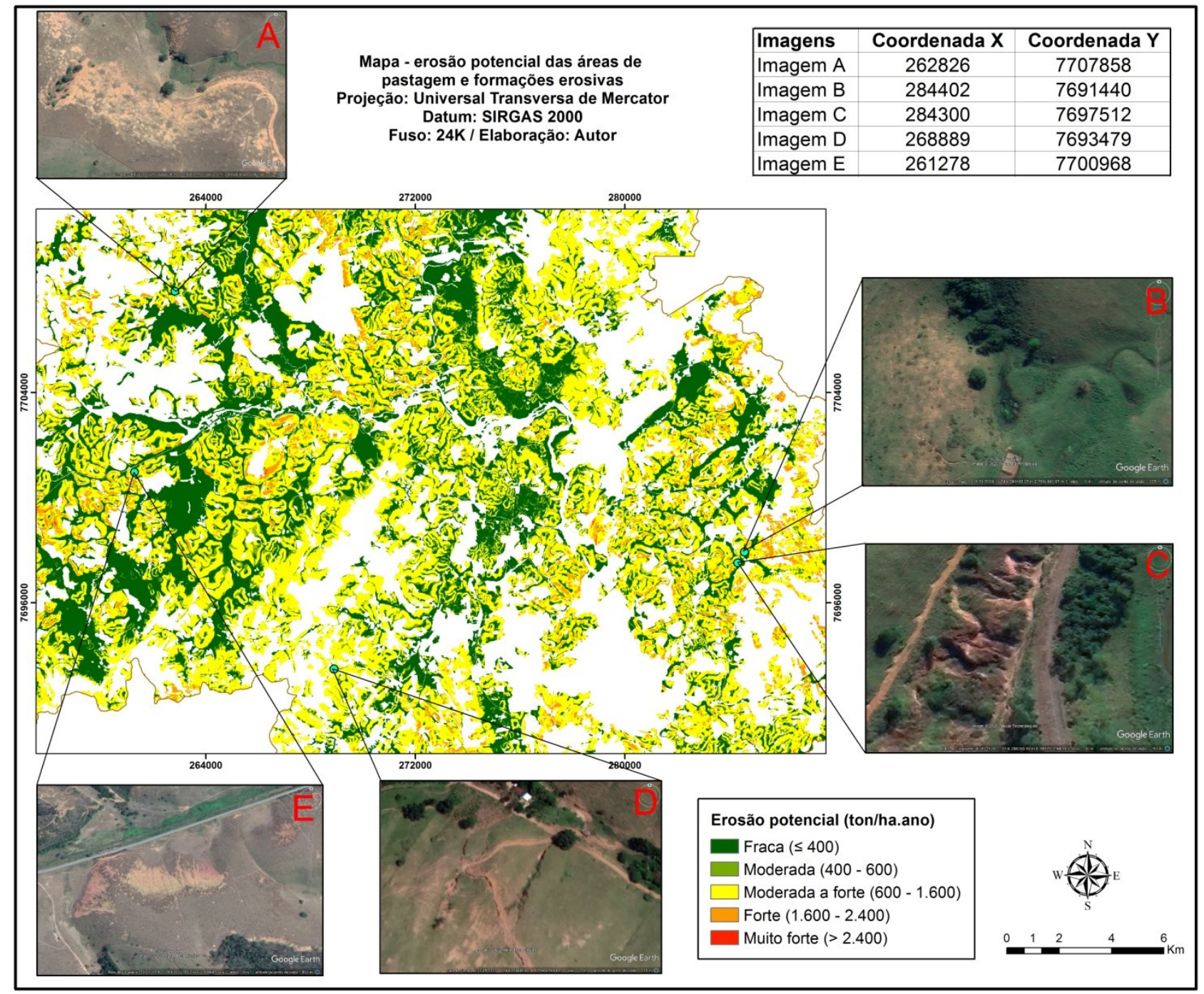

Fonte: O Autor (2020). 
Figura 5 - Erosão potencial e formações erosivas nas áreas de cafeicultura

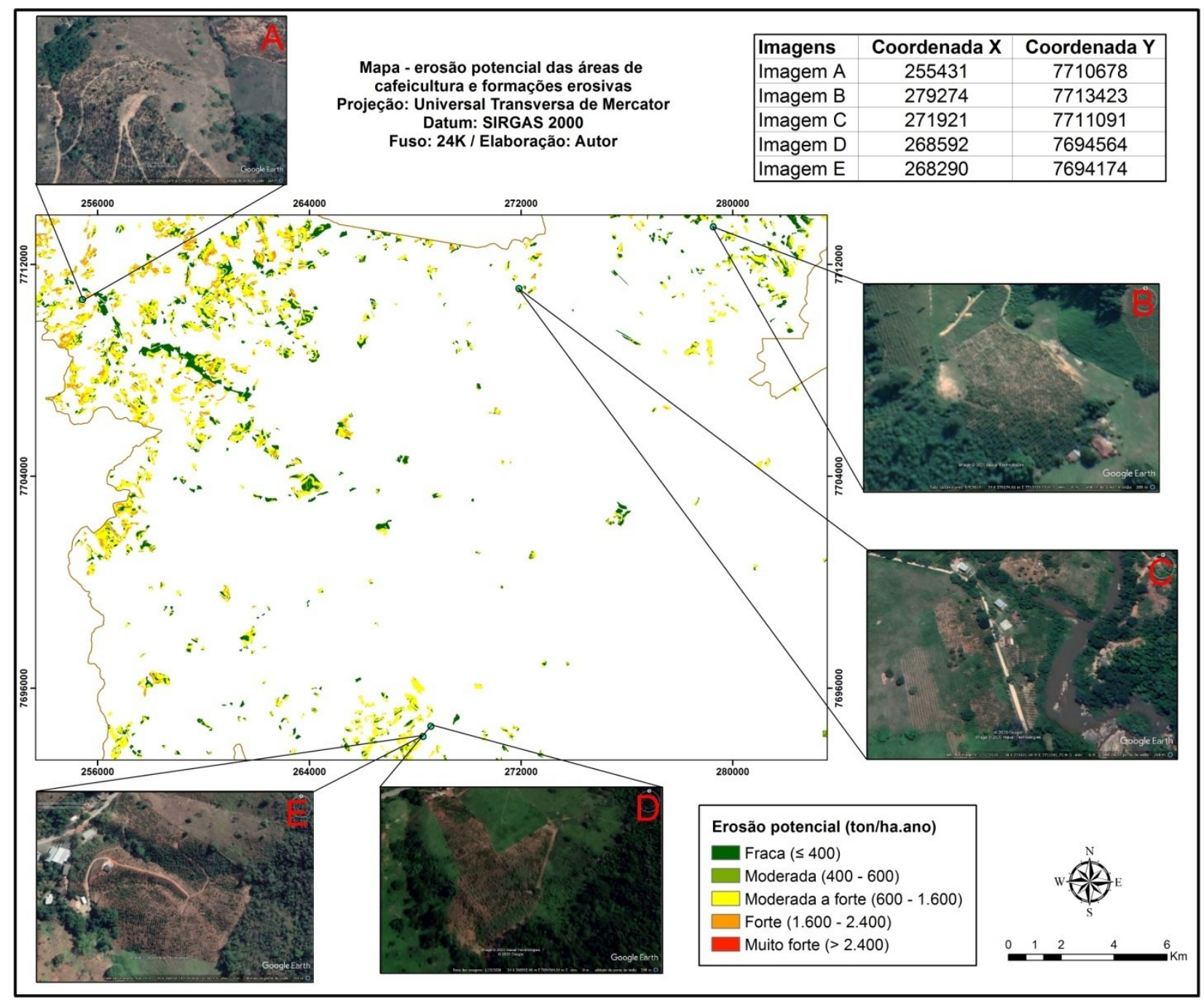

Fonte: O Autor (2020).

Nas áreas de pastagem, há erosão em sulcos (fendas deixadas pelo arado na superfície do solo), ravinas (sulcos provocados por escavamento gerado pelo escoamento superficial das águas pluviais ao sofrer certas concentrações de água (UERJ, 2020)) e voçorocas, principalmente nos espaços com tendência natural a erosão classificada como "moderada a forte". Além do mais, há formações erosivas dispostas muito próximas a nascentes, o que pode resultar, por exemplo, em assoreamento das mesmas, no que se refere à erosão hídrica do solo. A erosão em sulcos é formada a partir da concentração do escoamento superficial nas depressões da superfície do terreno, evoluindo para a formação de canais ou ravinas, o que faz aumentar a degradação dos solos pela erosão hídrica (BEZERRA et al., 2010). 
A voçoroca, de acordo com Tedesco, Antunes e Oliani (2014), ocasiona grandes perdas de solos e constituem os processos erosivos de maiores proporções e, consequentemente, de maiores prejuízos financeiros, sociais e ambientais. Já nos cafezais, há intenso predomínio da monocultura, com áreas de solo totalmente desprovido de vegetação. Além do mais, há lavouras cafeeiras nas condições mencionadas e muito próximas a cursos hídricos, o que pode desencadear impactos ambientais preocupantes, como a lixiviação de agroquímicos utilizados nas lavouras, a contaminação e o assoreamento das águas superficiais. A situação é muito preocupante para as áreas de cafeicultura e, principalmente, de pastagem, pelo fato da pecuária ser a principal atividade econômica rural no município.

Portanto, as formas de ocupação e manejo da cafeicultura e pecuária no município de Cachoeiro de Itapemirim são um grande motivo de preocupação em termos ambientais e econômicos. Tais áreas precisam urgentemente de medidas de mitigação e atenuação no que tange os processos erosivos, tendo em vista o estágio avançado da erosão em algumas áreas e o agravamento de formações erosivas. Nos cafezais, práticas como o café consorciado com feijão e roçado são importantes, pois, além de manter o solo coberto, colaboram com a ampliação da renda do produtor, com a reciclagem de nutrientes no solo e a redução de custos com capinas mecânicas (PAULA; CABANÊZ; FERRARI, 2013). Essa medida também traz maior proteção ao solo nos espaços desprovidos de cobertura vegetal, considerando o fato de que a falta de cobertura do solo entre os indivíduos cafeeiros e o emprego excessivo da monocultura representam os principais problemas na cafeicultura do município de Cachoeiro de Itapemirim, juntamente com a ocupação de grande parte das lavouras em locais com potencialidade moderada a forte à erosão hídrica.

Nas áreas de pastagem, é de extrema necessidade a adoção de técnicas, como a recuperação, renovação, restrição e suplementação de pastagens, sistemas de Integração Pecuária-Floresta (IPF), Lavoura-Pecuária (ILP) e Lavoura-Pecuária-Floresta (ILPF) (OLIVEIRA; MONTEBELLO, 2014). Já Fiorese e Leite (2018) propõem a formação de piquetes nas áreas de pasto, o que contribui para um melhor aproveitamento e desenvolvimento das pastagens. Nessa técnica, o espaço utilizado para pastagem é sempre o mesmo, não havendo necessidade de desmatar e desapropriar outras áreas da propriedade para o plantio de alimentos para os animais. Entretanto, quando uma parte da área de pastagem está sendo utilizada, a outra se encontra em repouso, havendo sempre uma alternância entre os piquetes de pastagem (NARDI et al., 2016). Tais medidas são de extrema necessidade, principalmente nas áreas de pasto em que ainda não há estágio avançado de erosão, no intuito de 
aumentar a cobertura vegetal, trazer maior proteção aos solos e, assim, evitar o aparecimento e agravamento de formações erosivas.

\section{CONCLUSÃO}

As áreas de pastagem e cafeicultura do município de Cachoeiro de Itapemirim possuem expressiva potencialidade natural à erosão, o que está embasado e se torna mais preocupante através da presença de diferentes formações erosivas. Além disso, esta pesquisa evidencia também uma preocupação em relação à ocupação dessas atividades econômicas no município abrangido, principalmente conforme o manejo da terra nas áreas mais propícias à erosão, o que pode trazer prejuízos econômicos, sociais e ambientais. O método da USLE apresenta ótima aplicação para a área, embora sejam necessários outros modelos matemáticos no intuito de melhor aferir a erosão potencial em escalas menores (bacia hidrográfica, por exemplo) dentro do município.

Principalmente na pecuária, é de grande necessidade a adoção de práticas que favoreçam a conservação da água e do solo e que sejam capazes de conscientizar o produtor rural, além da realização de pesquisas com ênfase nos impactos da erosão na cafeicultura e pecuária em termos socioambientais no município e com aplicação de outros modelos matemáticos de estimativa da erosão. Tais ações podem ser articuladas entre gestores públicos, pesquisadores, produtores rurais e comitê de bacias hidrográficas da região, a fim de trazer maior conservação do solo e dos recursos naturais e haver maior produtividade agrícola e pecuária na região.

\section{REFERÊNCIAS}

ANA - Agência Nacional de Águas. Encontre mapas interativos, conjuntos de dados geográficos, imagens de satélite e outros serviços. 2020. Disponível em: http://metadados.ana.gov.br/geonetwork/srv/pt/main.home. Acesso em: 1 jun. 2020.

ARCGIS. ArcGIS: Software. Disponível em http://www.esri.com/software/arcgis/index.html. Acesso em: 18 jun. 2018.

BARBOSA, A. F.; OLIVEIRA, E. F. de.; MIOTO, C. L.; PARANHOS FILHO, A. C. Aplicação da Equação Universal de Perda do Solo (USLE) em softwares livres e gratuitos. Anuário Geo, v. 38, n. 1, p. 170-179, 2015.

BERTONI, J.; LOMBARDI NETO, F. Conservação do solo. 4. ed. São Paulo: Ícone Editora, 1999.

BEZERRA, S. A.; CANTALICE, J. R. B.; CUNHA FILHO, M.; SOUZA, W. L. da S. Características hidráulicas da erosão em sulcos em um cambissolo do semiárido do Brasil. Rev. Bras. Ciênc. Solo, v. 34, n. 4, p. 1325-1332, 2010. DOI: http://dx.doi.org/10.1590/S0100-06832010000400029

CARVALHO, N. O. Hidrossedimentologia prática. 2. ed. Rio de Janeiro: Interciência, 2008. 
COSTA, A. L. C. da. Estudo da vulnerabilidade à erosão com a aplicação da Equação Universal de Perda de Solo na Alta Bacia Hidrográfica do Rio Jacaré Pepira, utilizando SIG/SPRING. 2005. 168 f. Dissertação (Mestrado em Geociências) - Universidade Estadual Paulista, Rio Claro, 2005.

DEMARCHI, J. C.; ZIMBACK, C. R. L. Mapeamento, erodibilidade e tolerância de perda de solo na sub-bacia do Ribeirão das Perobas. Energ. Agric., v. 29, n. 2, p. 102-114, 2014. DOI: https://doi.org/10.17224/EnergAgric.2014v29n2p102-114

DESMET, P. J. J.; GOVERS, G. A GIS procedure for automatically calculating the USLE LS factor on topographically complex landscape units. J. Soil Water Conserv., v. 51, n. 5, p. 427-433, 1996.

DURÃES, M. F.; MELLO, C. R. de. Distribuição espacial da erosão potencial e atual do solo na Bacia Hidrográfica do Rio Sapucaí, MG. Eng. Sanit. Ambient., v. 21, n. 4, p. 677-685, 2016. DOI: https://doi.org/10.1590/s1413-41522016121182

FERRÃO, R. G. FONSECA, A. F. A. da.; BRAGANÇA, S. M.; FERRÃO, M. A. G.; DE MUNER, L. H. Sustentabilidade da cafeicultura do Colinon no Espírito Santo. Vitória: INCAPER, 2007. $29 \mathrm{p}$.

FIORESE, C. H. U.; LEITE, V. R. Dinâmica do uso e cobertura do solo na sub-bacia hidrográfica do Ribeirão Estrela do Norte no município de Castelo, Estado do Espírito Santo. Agrar. Acad., Goiânia, v. 5, n. 10, p. 52-65, 2018. DOI: 10.18677/Agrarian_Academy_2018B6

GALDINO, S. Estimativa da perda de terra sob pastagens cultivadas em solos arenosos da bacia hidrográfica do Alto Taquari - MS/MT. 2012. 115 p. Tese (Doutorado em Engenharia Agrícola) - Universidade Estadual de Campinas, Campinas, 2012.

GALHARTE, C. A.; CRESTANA, S. Avaliação do impacto ambiental da integração lavourapecuária: Aspecto conservação ambiental no cerrado. Rev. Bras. Eng. Agr. Amb., Campina Grande, v. 14, n. 11, nov. 2010. DOI: https://doi.org/10.1590/S1415-43662010001100010

GEOBASES. IEMA - mapeamento ES - 2012-2015. 2020. Disponível em: https://geobases.es.gov.br/links-para-mapes1215. Acesso em: 1 jun. 2020.

GOOGLE EARTH. Website. Disponível em: http://earth.google.com/. Acesso em: 14 fev. 2016.

IJSN - Instituto Jones dos Santos Neves. Shapefiles. 2020. Disponível em: http://www.ijsn.es.gov.br/mapas/. Acesso em: 8 jul. 2020.

INCAPER - Instituto Capixaba de Pesquisa, Assistência Técnica e Extensão Rural. Programa de assistência técnica e extensão rural PROATER 2011 - 2013: Cachoeiro de Itapemirim. 2010. Disponível em: https://incaper.es.gov.br/media/incaper/proater/municipios/Caparao/Cachoeiro.pdf. Acesso em: 9 jul. 2020.

LANZANOVA, M. E. Efeito de sistemas de culturas em plantio direto na erosão e propriedades de um argissolo vermelho. 2009. 264 p. Tese (Doutorado em Engenharia Agrícola) - Universidade Federal de Santa Maria, Santa Maria, 2009.

LOMBARDI NETO, F.; MOLDENHAUER, W. C. Erosividade da chuva: sua distribuição e relação com as perdas de solo em Campinas (SP). Rev. Bragantia, Campinas, v. 51, n. 2, p. 189-196, 1992. DOI: https://doi.org/10.1590/S0006-87051992000200009

LOPES, P. R.; ARAÚJO, K. C. S.; LOPES, I. M.; RANGEL, R. P.; SANTOS, N F. de F.; KAGEYAMA, P. Y. Uma análise das consequências da cafeicultura convencional e as opções de modelos sustentáveis de produção - agricultura orgânica e agroflorestal. Rev. Esp. Diál. Desc., 
Araraquara, v. $8, \quad$ n. 1 , p. 1-38. 2014. DOI: https://doi.org/10.32760/19841736/REDD/2014.v8i2.6912

MARQUES, J. F.; LOMBARDI NETO, F.; BACELLAR, A. A. A. Erosão dos solos: indicadores físicos e econômicos. In: MARQUES, J. F.; SKORUPA, L. A.; FERRAZ, J. M. G. (Ed). Indicadores de sustentabilidade em agroecossistemas. Jaguariúna: Embrapa Meio Ambiente, 2003.

MATA, C. L. Análise multitemporal da susceptibilidade erosiva na bacia do Rio Urucuia (MG) por meio da Equação Universal de Perda de Solos. 2009. 71 f. Dissertação (Mestrado em Geografia) - Universidade de Brasília, Brasília, 2009.

MCCOOL, D. K.; BROWN, L. C.; FOSTER, G. R. Revised slop steepness factor of the Universal Soil Loss Equation. Trans. ASAE, v. 30, n. 5, p. 1387-1396, 1987. DOI: 10.13031/2013.30576

MCCOOL, D. K.; FOSTER, G. R.; MUTCHLER, C. K.; MEYER, L. D. Revised slope length factor for the Universal Soil Loss Equation. Trans. ASAE, v. 32, n. 5, p. 1571-1576, 1989. DOI: $10.13031 / 2013.31192$

MELLO, G. de.; BUENO, C. R. P.; PEREIRA, G. T. Variabilidade espacial de perdas de solo, do potencial natural e risco de erosão em áreas intensamente cultivadas. Rev. Bras. Eng. Agr. Amb., Campina Grande, v. 10, n. 2, abr./jun. 2006. DOI: https://doi.org/10.1590/S141543662006000200010

MORAIS, R. C. de S.; SALES, M. C. L. Estimativa do Potencial Natural de Erosão dos Solos da bacia hidrográfica do Alto Gurguéia, Piauí-Brasil, com uso de Sistema de Informação Geográfica. Cad. Geog., v. 27, n. 1, p. 84-105, 2017. DOI: https://doi.org/10.5752/p.23182962.2017v27nesp1p84

NARDI, A. C.; LOCH, P.; DE CONTO, A. G.; MENEGHATTI, M. R.; DE FARIÑA, L. O. Impactos ambientais da pecuária de leite da agricultura familiar. Com. Sus., v. 3, n. 2, p. 49-66, jul./dez. 2016.

OLIVEIRA, R. L.; BARBOSA, M. A. A. de F.; BAGALDO, A. R.; RIBEIRO, M. D. O zootecnista e os sistemas de Produção de bovinos de corte. In: CONGRESSO BRASILEIRO DE ZOOTECNIA, 18., 2008, João Pessoa. Anais... João Pessoa: Associação Brasileira de Zootecnistas, 2008.

OLIVEIRA, A. P. N.; MONTEBELLO, A. E. S. Aspectos econômicos e impactos ambientais da pecuária bovina de corte brasileira. Rev. UNAR, v. 9, n. 2, p. 1-20, 2014.

PAULA, M.; CABANÊZ, P.; FERRARI, J. Desgaste superficial do solo em cafeicultura capixaba de montanha em função do manejo da vegetação espontânea. Eng. Amb., Espírito Santo do Pinhal, v. 10, n. 2, p. 90-104, mar./abr. 2013.

PARENTE, H. N.; MAIA, M. O. Impacto do pastejo sobre a compactação dos solos com ênfase no Semiárido. Tróp.: Ci. Agr. Biol., v. 5, n. 3, p. 3-15, 2011. DOI: http://dx.doi.org/10.0000/rtcab.v5i3.272

ROCHA, A. C. da.; PREZOTTI, L. C.; DADALTO, G. G. Práticas de conservação de solo em café arábica na região serrana do Espírito Santo. In: SIMPÓSIO DE PESQUISA DOS CAFÉS DO BRASIL, 2000, Poços de Caldas. Anais... Poços de Caldas: Consórcio Pesquisa Café, 2000. p. 13761378.

SILVA, R. M.; PAIVA, F. M. L.; SANTOS, C. A. G. Análise do grau de erodibilidade e perdas de solo na sub-bacia do Rio Capiá baseado em SIG e sensoriamento remoto. Rev. Bras. Geog. Fís., Recife, v. 2, n. 1, p. 26-40, 2009. DOI: https://doi.org/10.26848/rbgf.v2.1.p26-40 
SOUZA, V.; GASPARETTO, N. V. L. Aplicação da Equação Universal de Perdas de Solo (EUPS) na bacia do córrego Pinhalzinho Segundo, Noroeste do Paraná. Rev. Bras. Geomorf., v. 13, n. 3, p. 267-278, jul./set. 2012. DOI: http://dx.doi.org/10.20502/rbg.v13i3.191

TEDESCO, A.; ANTUNES, A. F. B.; OLIANI, L. O. Detecção de formação erosiva (voçoroca) por meio de classificação hierárquica e por árvore de decisão. Bol. de Ciênc. Geodésicas, Curitiba, v. 20, n. 4, p. 1005-1026, out./dez. 2014. DOI: https://doi.org/10.1590/S1982-21702014000400055

UERJ. Ravinas. 2020. Disponível em: http://www.bvambientebf.uerj.br/arquivos/ravinas.htm. Acesso em: 14 jul. 2020.

WUST, C.; TAGLIANI, C.; CONCATO, A. C. A pecuária e sua influência impactante ao meio ambiente. In: CONGRESSO BRASILEIRO DE GESTÃO AMBIENTAL, 6., 2015, Porto Alegre. Anais... Porto Alegre: IBEAS, 2015.

WISCHMEIER, W. H.; SMITH, D. D. Rainfail erosion. Adv. Agron., New York, n. 14, p. 109-148, 1962. DOI: https://doi.org/10.1016/S0065-2113(08)60437-X 